Donal Buggy MSC MRCPI DME FFARCSI, Patrick Higgins FFARCSI, Ciaran Moran FFARCSI, Frances O'Donovan FFARCSI, Maire McCarroll FFARCSI

\title{
Clonidine at induction reduces shivering after general anaesthesia
}

Purpose: Postanaesthetic shivering occurs in 5-65\% of patients. In addition to causing discomfort, it is associated with deleterious consequences. Our objective was to investigate the effect of $150 \mu \mathrm{g}$ clonidine, at induction of anaesthesia, on perioperative core and peripheral temperature, incidence of postanaesthetic shivering and patients' perception of cold.

Methods: Sixty ASA I or 2 patients scheduled for elective orthopaedic limb surgery were randomly allocated to group I, who received $150 \mu \mathrm{g}$ clonidine $i v$, or group 2 , who received a saline bolus $i v$, before induction. In all patients, anaesthesia was induced with fentanyl and propofol and maintained by spontaneous respiration (via a laryngeal mask airway) of oxygen, nitrous oxide and enflurane. Core (nasopharyngeal) and peripheral (dorsal hand) temperatures were recorded at induction and 15-min intervals. Nurses, unaware of the treatment groups, recorded visible shivering in the recovery room. When cognitive function returned, patients were asked to grade their perception of cold on a $10 \mathrm{~cm}$ linear analogue scale, higher scores indicating heat discomfort.

Results: While core temperature decreased and peripheral temperature increased in both groups, there was no difference between the groups at any time. However, there was a lower incidence of shivering in the clonidine group ( $20 \%$ vs $66.7 \%, P<0.001)$. Patients receiving clonidine felt warmer; thermal comfort score (median interquartile range) $5.9(5.0-7.2)$ vs $5.0(4.5-6.0), P<0.05)$.

Conclusion: Clonidine $150 \mathrm{~g}$ iv at induction of anaesthesia reduces the incidence of shivering and patients' subjective perception of cold on emergence from general anaesthesia.

Objectif : Le frisson survient chez $5 \%$ à $65 \%$ des patients après l'anesthésie. En plus d'incommoder, le frisson a des conséquences nocives. Cette étude visait à étudier les effets de la clonidine $150 \mu \mathrm{g}$ administrée à linduction de l'anesthésie sur les températures périphériques et centrales, lincidence du frisson postanesthésique et la façon dont le patient perçoit le froid.

Méthodes : Soixante patients ASA / et 2 programmés pour une intervention orthopédique sur les membres avaient eté répartis au hasard: avant l'induction, le groupe I recevait $150 \mu \mathrm{g}$ de clonidine iv et le groupe 2 recevait un bolus de sol.phys. Lanesthésie était toujours induite au fentanyl avec propofol et maintenue au protoxyde d'azote et à l'enflurane. Les températures centrales (pharyngées) et périphériques (dos de la main) étaient enregistrées à l'induction et à des intervalles de cinq minutes par la suite. Des infirmières, ignorant le groupe du patient, enregistraient le frisson apparent en salle de réveil. Au retour des fonctions cognitives, on demandait aux patients d'évaluer leur perception du frojd sur une échelle visuelle analogique de $10 \mathrm{~cm}$, les scores élevés étant attribués selon l'importance du malaise provoqué par le froid.

Résultats : Alors que la température centrale diminuait et la température périphérique augmentait dans les deux groupes, aucune différence n'était notée entre les groupes. Cependant, l'incidence du frisson était plus basse dans le groupe clonidine ( $20 \%$ vs $66,7 \%, P<0,001)$. La perception de chaleur était plus élevée chez les patients sous clonidine avec un score de comfort (médiane écart interquartile de) $5.9(5,0-7.2)$ vs $5.0(4,5-6,0), P<0,05$ ).

Conclusion : Administrée à l'induction, la clonidine iv réduit l'incidence du frisson et la sensation subjective de froid perçue au réveil après une anesthésie générale.

From the Department of Anacsthesia, Cappagh Orthopaedic Hospital, Dublin, 11, Ireland. Address correspondence to: Dr. Donal Buggy, Department of Anaesthesia, St. James' Hospital, Dublin, 8, Ireland.

Phone: 353-1-4537941 Ext. 2516.

Accepted for publication November 10, 1996. 
$\mathrm{P}$ OST anaesthetic shivering affects up to $65 \%$ of patients after general or regional anaesthesia, ${ }^{1}$ and may be very distressing for patients. ${ }^{2}$ Moreover, it may have a number of deleterious consequences including increased oxygen consumption, cardiac output, carbon dioxide production and circulating catecholamines $s^{2,3}$ in addition to raised intra-ocular pressure. ${ }^{4}$ Furthermore, postanaesthetic shivering is associated with decreased mixed venous oxygen saturation ${ }^{5}$ and interference with monitoring. ${ }^{6}$ A variety of physical (radiant heaters, increased ambient temperature, space blankets ${ }^{7-9}$ ) and pharmacologi$\mathrm{cal}^{10-12}$ methods have attempted to reduce perioperative hypothermia and suppress postanaesthetic shivering but none has received universal acceptance. Prevention of onset of shivering may be a more valuable approach as evidenced by a recent study demonstrating the benefit of pre-emptive use of the space blanket.9

Clonidine, an imidazole with alpha $\mathrm{a}_{2}$ adrenergic agonist activity has documented antihypertensive and analgesic properties ${ }^{13}$ In addition, it has reduced the incidence of established postanaesthetic shivering. ${ }^{14}$ Hypotension and sedation are reported side-effects. ${ }^{15,16}$ This study was designed to evaluate the effect of giving clonidine as a single bolus at induction of anaesthesia on perioperative core and peripheral temperature, intraoperative blood pressure, incidence of post anaesthetic shivering and time to discharge from recovery room.

\section{Patients and methods}

After institutional ethics committee approval and informed written consent, 60 ASA 1 or 2 patients, male or female, aged 16-65 yr were studied. All patients underwent elective short, peripheral, surgical procedures (i.e., without opening body cavities) of about one hour duration. Patients receiving regular medication, who required mechanical ventilation or whose procedure was likely to be $>90$ min duration were excluded: Patients were randomized into two groups. Group I received $150 \mu \mathrm{g}$ clonidine iv prior to induction. Group 2 received $1 \mathrm{ml}$ normal saline prior to induction. Patients were asked to rate their thermal comfort on a $10 \mathrm{~cm}$ rating scale. ${ }^{17}$ A value of 10 indicated extreme heat discomfort, 1 indicated extreme cold discomfort. This rating was again taken in recovery room, when patients had regained sufficient cognitive function.

A standard anaesthetic technique was used. Anaesthesia was induced with $\mathrm{l} \mu \mathrm{\mu g} \cdot \mathrm{kg}^{-1}$ fentanyl, 2-3 mg. $\mathrm{kg}^{-1}$ propofol. A laryngeal mask airway was inserted and anaesthesia maintained by spontaneous respiration of nitrous oxide $70 \%$ and enflurane $1.5-2.5 \%$ in oxygen. One litre intravenous fluid at room temperature was administered. Standard monitoring included: ECG, non-invasive blood pressure, pulse oximetry, end-tidal carbon dioxide and fractional inspired oxygen. A standard semi-closed circuit, with gas flows corresponding to the estimated alveolar minute ventilation of the patient (range $5-81 \cdot \mathrm{min}^{-1}$ ) and incorporating a condenser humidifier was used in all patients. Ambient temperature and relative humidity were strictly maintained within the limits of $21.9-$ $22.2^{\circ} \mathrm{C}$ and $59-61 \%$ respectively. Airflow was maintained constant in the operating theatre. All patients received standard surgical draping. A naso-pharyngeal temperature probe was positioned immediately after induction as an index of core temperature. Peripheral skin temperature was obtained from a thermistor positioned on the dorsum of the hand. Naso-pharyngeal and skin temperatures were recorded at induction and every $15 \mathrm{~min}$ intra-operatively. Skin temperature was recorded in the recovery room. Shivering was assessed as an all-or-nothing phenomenon by recovery staff who were unaware of the study groups. Shivering was defined as readily detectable fasiculations and tremor of the jaw, neck, trunk and extremities lasting $>20 \mathrm{sec}$.

In a previous study, we found a $39 \%$ incidence of shivering. Taking a $30 \%$ difference between groups in the proportion of shivering patients as clinically important, 30 patients would be required in each group to demonstrate such a difference with power to detect a true difference of $>\mathbf{8 0} \%$. Chi-squared test was used to compare incidences of shivering. Blood pressure and temperature values were compared using within group analysis of variance and unpaired t-test for differences between the groups. Thermal comfort scores were compared using Mann-Whitney $U$ test for skewed data. $P<0.05$ was considered significant.

\section{Results}

Patients in both groups were similar in demographic data and duration of anaesthesia, (Table I). Overall incidence of shivering observed was $43 \%: 66.7 \%$ in the control group compared with $20 \%$ in the clonidine group $(P<0.001$, Table II). This yields an odds ratio of 0.125 for the effect of clonidine on postanaesthetic shivering, i.e., an eight-fold reduction in the risk of shivering. The $95 \%$ confidence interval for this difference in the proportion of shivering patients is $25-69 \%$, while the $95 \%$ confidence interval for the odds ratio is 0.032-0.46 (Table II).

Although core temperature decreased slightly up to $45 \mathrm{~min}$ of anaesthesia, and peripheral temperature increased over the full duration studied in both groups, there were no differences between the groups at any time (Figures 1 and 2). Lowest systolic blood 
TABLE I Patient characteristics

\begin{tabular}{lcc}
\hline & Clonidine & Control \\
\hline Age $(\mathrm{yr}$, range $)$ & $30.0 \pm 11.7(16-65)$ & $27.6 \pm 9.8(15-55)$ \\
Sex $(\mathrm{M} / \mathrm{F})$ & $20 / 10$ & $23 / 7$ \\
$\begin{array}{l}\text { Duration anaesthesia } \\
(\mathrm{min})\end{array}$ & $59.7 \pm 20.2$ & $64.8 \pm 24.3$ \\
\hline
\end{tabular}

Mean $\pm S D$ or median (interquartile range).

TABLE II Incidence of shivering

\begin{tabular}{lcc}
\hline & $\begin{array}{c}\text { Clonidine } \\
\text { Control }\end{array}$ & $\begin{array}{c}(n=30) \\
(n=30)\end{array}$ \\
\hline Shivering $(n=26)$ & 6 & 20 \\
No Shivering $(n=34)$ & 24 & 10 \\
\hline
\end{tabular}

Chi-square (with Yates' correction) $=11.46, P<0.001$; $95 \%$ Confidence Interval for difference in proportion $=25-69 \%$; Odds Ratio $=0.125$ for protective effect of clonidine; $95 \%$ Confidence Interval for the odds ratio $=0.032-0.46$

TABLE III Blood pressure, thermal comfort scores (TCS) and time in recovery room.

\begin{tabular}{lcc}
\hline & Clonidine & Control \\
\hline Baseline systolic BP (mm Hg) & $116.5 \pm 11.6$ & $113.9 \pm 10.2$ \\
Lowest intra-operative systolic & & \\
BP (mm Hg) & $96.2 \pm 7.4$ & $97.2 \pm 6.7$ \\
Baseline TCS & $5.1(4.7-5.2)$ & $5.0(4.7-5.2)$ \\
Recovery room TCS* & $5.9(5.0-7.2)$ & $5.0(4.5-6.0)$ \\
Time in recovery room (min) & $25.1 \pm 3.9$ & $23.6 \pm 4.7$ \\
\hline
\end{tabular}

Mean \pm SEM or median (interquartile range).

${ }^{\star} P<0.05$, Mann-Whitncy U test

pressure and time to discharge from the recovery room were also similar in both groups. Patients receiving clonidine had higher mean thermal comfort scores (TCS), (5.0-7.2) vs 5.0 (4.5-6.0), median (interquartile range), $P<0.05$ ) suggesting that these patients felt subjectively warmer than their counterparts in the control group (Table III).

\section{Discussion}

We have demonstrated that spontaneously breathing patients, treated at induction of general anaesthesia with clonidine $150 \mu \mathrm{g} i \mathrm{p}$, have a reduced incidence of post-operative shivering. This reduction in shivering was obtained without any difference in peripheral or core temperatures between the two groups. Moreover, clonidine was not associated with lower blood pressures or longer time to discharge from recovery room, although sedation was not formally assessed. Our data also suggest that patients receiving

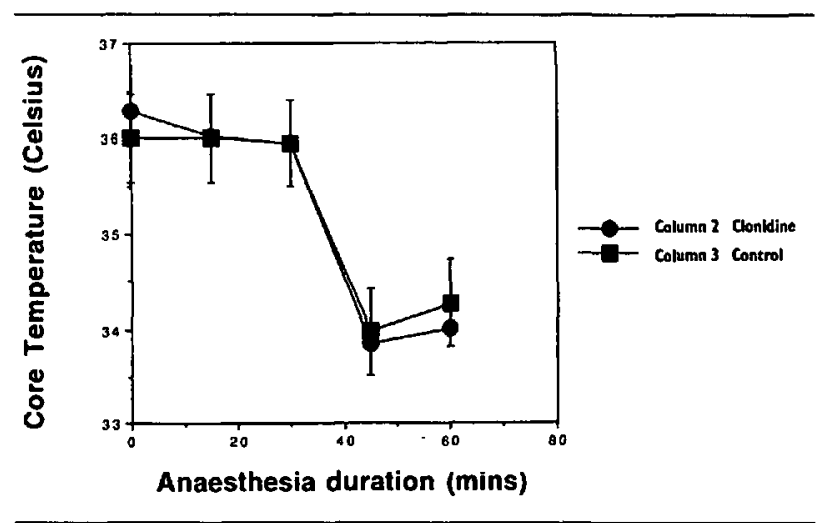

FIGURE 1 Core Temperature

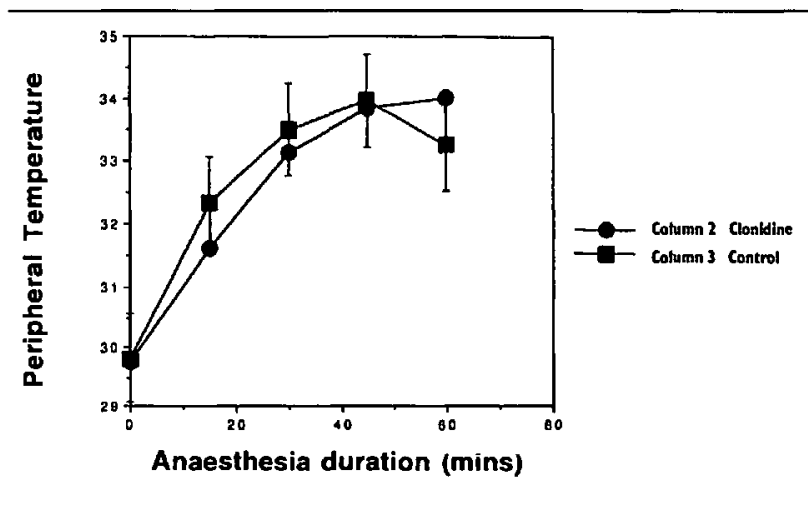

FIGURE 2 Peripheral Temperatures

clonidine felt warmer than those receiving saline, but all patients had TCS close to feeling thermally neutral. While there is a large difference in the proportion of shivering patients in our study groups ( $66.7 \%$ controls ps $20 \%$ clonidine), the $95 \%$ confidence interval is $25-69 \%$, a relatively wide range, which casts some uncertainty on the statistical authority of the chisquared result. Nevertheless, we believe that most clinicians would accept a $25 \%$ difference in the incidence of shivering (the lower limit of our $95 \%$ confidence interval range) as being of clinical importance. In addition, a Type 1 error is unlikely in the presence of a larger difference than we set out to detect at the $P<0.05$ level (47\% compared with $30 \%$ ). ${ }^{18}$

Postanaesthetic shivering is a potential complication for any surgical patient. Contributory factors include patients' age and sex, aspects of the anaesthetic technique such as pre-medication, propofol and spontaneous ventilation. ${ }^{1,19-21}$ During general anaesthesia, there is core-to-peripheral redistribution of body heat, reflecting the increased cutaneous blood flow induced by vasodilatory anaesthetic agents. $1,8,22$ 
Heat may subsequently be lost from the skin by convection and radiation. Anaesthetic agents reduce the shivering threshold, ${ }^{22}$ thus core temperature loss continues unchecked. On emergence from anaesthesia, the normal shivering threshold is restored, stimulating abrupt shivering. Clonidine, too, reduces the thermoregulatory threshold for shivering, ${ }^{23}$ yet our data and others' demonstrate its antishivering efficacy. This suggests that alpha ${ }_{2}$ adrenergic neural pathways may be involved in the control of shivering.

A recent editorial suggested that peripheral, rather than core, afferent thermal signals may have more influence on the genesis of postanaesthetic shivering. ${ }^{24}$ The precise mechanism by which clonidine inhibits shivering remains unclear, but it has central and peripheral effects which may explain its anti-shivering activity ${ }^{25}$ Clonidine induces cutaneous vaso-constriction secondary to stimulation of peripheral receptors. ${ }^{26}$ However, such vaso-constriction should reduce skin temperature, stimulate cutaneous cold thermoreceptors and aggravate shivering. Thus, a peripheral mechanism seems to have only a minor role in the effect of clonidine on shivering. Our study confirms that there was no difference between the measured peripheral temperatures of the clonidine and control groups at each time interval. However, clonidine may centrally inhibit the transmission of afferent thermal signals at the level of the spinal cord or have an inhibitory action on the hypothalamus. The density of alpha, adrenergic receptors in the hypothalamus and the observation that central administration of noradrenaline decreases core temperature supports this hypothesis. ${ }^{13,25}$

While Joris et al. showed that clonidine suppressed established shivering, ${ }^{12}$ Delaunay and Hommeril ${ }^{14,26}$ found that it prevented the onset of shivering when given immediately postoperatively. One report demonstrated a reduction in shivering with clonidine po before coronary artery bypass graft surgery. ${ }^{27}$ Induced hypothermia may have influenced thermoregulatory behaviour in this case, however. In contrast to Quintin et al. who found that patients receiving clonidine regained core temperature at the same rate as controls but that peripheral temperature recovered more slowly, ${ }^{25}$ our data showed no difference in core or peripheral temperatures intraoperatively, and no difference in peripheral temperature in recovery.

Our study is limited by its reliance on human observation of the occurrence of shivering, albeit according to prospectively defined criteria. We did not include assessment of shivering intensity, believing it to be even more subjective. Electromyographic data would provide an objective and quantitative measurement of shiv- ering. ${ }^{28}$ Although we did not prospectively control for the use of a surgical tourniquet on the lower limb, 50\% $(15 / 30)$ of our clonidine group and $57 \%(17 / 30)$ of our control group had a lower limb tourniquet applied. Whether this factor would have influenced the incidence of postanaesthetic shivering is unknown. We did not document the phase of the menstrual cycle in our female subjects, which is known to influence postanaesthetic shivering. ${ }^{20}$ Nevertheless, the proportion of females and patients requiring a tourniquet was similar in each of our groups, thus it is unlikely that these issues would have altered the outcome. Although our clonidine patients had a similar time to discharge from recovery compared with controls, formal assessment of the sedative effect of clonidine in ambulatory patients has yet to be reported.

In conclusion, our data indicate a considerable reduction in post-anaesthetic shivering in patients treated with $150 \mu \mathrm{g}$ clonidine $i v$ at induction of anaesthesia, which was not associated with haemodynamic sequelae.

\section{Acknowledgment}

We thank our anaesthetic and recovery room nurses for their wholehearted co-operation.

\section{References}

1 Crossley AWA. Six months of shivering in a district general hospital. Anaesthesia 1992; 47: 845-8.

2 Brownbridge $P$. Shivering related to epidural blockade with bupivacaine in labour, and the influence of epidural pethidine. Anaesth Intensive Care 1986; 14: 412-7.

3 Ciofolo MJ, Clergue F, Devilliers C, Ben Ammar M, Viars $P$. Changes in ventilation, oxygen uptake, and carbon dioxide output during recovery from isoflurane anesthesia. Anesthesiology 1989: 70: 737-41.

4 Mahajan RP, Grover VK, Sharma SL, Singh $H$. Intraocular pressure changes during muscular hyperactivity after general anesthesia. Anesthesiology 1987; 66: 419-21.

5 Kaplan JA, Guffin AV. Shivering and changes in mixed venous oxygen saturation after cardiac surgery. (Abstract) Anesth Analg 1985; 64: 235.

6 De Courcy JG. Artefactual hypotension from shivering (Letter). Anaesthesia 1989; 44: 787-8.

7 Sharkey A, Lipton JM, Murphy MT, Giesecke AH. Inhibition of postanesthetic shivering with radiant heat. Anesthesiology 1987; 66: 249-52.

8 Morris RH, Wilkey $B R$. The effects of ambient temperature on patient temperature during surgery not involving body cavitics. Anesthesiology 1970; 32: 102-7. 
9 Buggy $D$, Hughes $N$. Pre-emptive use of the space blanket reduces shivering after general anaesthesia. Br J Anaesth 1994; 72: 393-6.

10 MacIntyre PE, Pavlin EG. Dwersteg JF. Effect of meperidine on oxygen consumption, carbon dioxide production, and respiratory gas exchange in postanesthesia shivering. Anesth Analg 1987; 66: 751-5.

11 Pauca $A L$, Savage RT, Simpson S, Roy RC. Effect of pethidine, fentanyl and morphine on post-operative shivering in man. Acta Anaesthesiol Scand 1984; 28: 138-43.

12 Joris J, Banache M, Bonnet F, Sessler DI, Lamy $M$. Clonidine and ketanserin both are effective treatment for postanesthetic shivering. Anesthesiology 1993; 79 : 532-9.

13 Maze $M$, Tranquilli $W$. Alpha - 2 adrenoceptor agonists: defining the role in clinical anesthesia. Anesthesiology 1991; 74: 581-605.

14 Delaunay L, Bonnet $F$, Duvaldestin P. Clonidine decreases postoperative oxygen consumption in patients recovering from general anaesthesia. Br J Anaesth 1991; 67: 397-401.

15 O'Meara ME, Gin T. Comparison of $0.125 \%$ bupivacaine with $0.125 \%$ bupivacaine and clonidine as extradural analgesia in the first stage of labour. $\mathrm{Br} \mathrm{J}$ Anacsth 1993; 71: 651-6.

16 Eisenach JC, Lysak SZ, Viscomi CM. Epidural clonidine analgesia following surgery: Phase I. Anesthesiology 1989; 71: 640-6.

17 Sessler DI, Ponte J. Shivering during epidural anesthesia. Anesthesiology 1990; 72: 816-21.

18 Altman DG, Gore GM, Gardner MJ, Pocock SJ. Statistical guidelines for contributors to medical journals. In: Gardner MJ, Altman DG (Eds.). Statistics with Confidence, Confidence Intervals and Statistical Guidelines. London: BMJ, 1989.

19 Baxendale BR, Mahajan RP, Crossley AWA. Anticholinergic premedication influences the incidence of postoperative shivering. $\mathrm{Br}$ J Anaesth 1994; 72: 291-4.

20 Tighe KE, Cartwright DP, Crossley AWA. Phase of the menstrual cycle influences the incidence of post-anaesthetic shivering. Br J Anaesth 1994; 73: $721 \mathrm{P}$.

21 Singh $P$, Harwood $R$, Cartwright DP, Crossley AWA. A comparison of thiopentone and propofol with respect to the incidence of postoperative shivering. Anaesthesia 1994; 49: 996-8.

22 Jensen $D$. The Principles of Physiology. New York: Appleton Century-Crofts, 1980; 1005-8.

23 Delaunay L, Bonnet $F$, Liu $N$, Beydon L, Catoire P, Sessler DI. Clonidine comparably decreases the thermoregulatory thresholds for vasoconstriction and shivering in humans. Anesthesiology 1993; 79: 470-4.

24 Crossley $A W A$. Postoperative shivering: the influence of body temperature. BMJ 1995; 311: 764-5.
25 Quintin $L$, Roudot $F$, Roux $C$, et al. Effect of clonidine on the circulation and vasoactive hormones after aortic surgery. Br J Anaesth 1991; 66: 108-15.

26 Hommeril JL, Bernard JM, Passuti N, Pinaud $M$, Souron $R$. Effects of intravenous clonidine on postoperative shivering. (French). Ann Fr Anesth Reanim 1991; 10: 554-8.

27 Flacke JW, Bloor BC, Flacke WE, et al. Reduced narcotic requirement by clonidine with improved hemodynamic and adrenergic stability in patients undergoing coronary bypass surgery. Anesthesiology 1987; 67: 11-9.

28 Tremblay LE, Bedard PJ. Effect of clonidine on motoneuron excitability in spinalized rats. Neuropharmacology 1986; 25: 41-6. 